\title{
Saccharomyces cerevisiae strain 905 reduces the translocation of Salmonella enterica serotype Typhimurium and stimulates the immune system in gnotobiotic and conventional mice
}

Correspondence Jacques R. Nicoli jnicoli@icb.ufmg.br

Received 16 January 2006 Accepted 2 November 2006
Flaviano S. Martins, ${ }^{1,2,3}$ Ana Cristina P. Rodrigues, ${ }^{4}$ Fabiana C. P. Tiago, ${ }^{1}$ Francisco J. Penna, ${ }^{2}$ Carlos A. Rosa, ${ }^{1}$ Rosa M. E. Arantes, ${ }^{5}$ Regina M. D. Nardi, ${ }^{1}$ Maria J. Neves ${ }^{3}$ and Jacques R. Nicoli ${ }^{1}$

${ }^{1}$ Departamento de Microbiologia, Instituto de Ciências Biológicas, Universidade Federal de Minas Gerais, C.P. 486, 30161-970, Belo Horizonte, MG, Brazil

${ }^{2}$ Departamento de Pediatria, Faculdade de Medicina, Universidade Federal de Minas Gerais, C.P. 486, 30161-970, Belo Horizonte, MG, Brazil

${ }^{3}$ Centro de Desenvolvimento da Tecnologia Nuclear/Comissão Nacional de Energia Nuclear (CDTN/CNEN), Belo Horizonte, MG, Brazil

${ }^{4}$ Faculdade de Medicina, UNIFENAS, Belo Horizonte, MG, Brazil

${ }^{5}$ Departamento de Patologia Geral, Instituto de Ciências Biológicas, Universidade Federal de Minas Gerais, C.P. 486, 30161-970, Belo Horizonte, MG, Brazil

Previous results in the laboratory of the authors showed that Saccharomyces cerevisiae strain 905, isolated during 'cachaça' production, was able to colonize and survive in the gastrointestinal tract of germ-free and conventional mice, and to protect these animals against oral challenge with Salmonella enterica serotype Typhimurium or Clostridium difficile. In the present work, the effects of S. cerevisiae 905 on the translocation of Salm. Typhimurium (mesenteric lymph nodes, Peyer's patches, spleen, liver) as well as on the immune system (number of Küpffer cells, immunoglobulin production, clearance of Escherichia coli $\mathrm{B}_{41}$ ) were evaluated in gnotobiotic and/or conventional mice. The treatment with the yeast reduced significantly the translocation of Salm. Typhimurium to liver in gnotobiotic animals and to all the organs tested in conventional mice. The number of Küpffer cells per 100 hepatocytes in liver was significantly higher $(P<0.05)$ in yeast mono-associated mice $(52.9 \pm 15.7)$ than in germ-free controls $(38.1 \pm 9.0)$. Probably as a consequence, clearance of $E$. coli $\mathrm{B}_{41}$ from the bloodstream was more efficient in yeast mono-associated animals when compared to germ-free mice. Higher levels $(P<0.05)$ of secretory $\lg \mathrm{A}$ in intestinal content and of $\lg \mathrm{A}$ and $\lg \mathrm{M}$ in serum were observed in yeast mono-associated mice when compared to germ-free group. Concluding, the protection against pathogenic bacteria observed in a previous study was probably due to a modulation of both local and systemic immunity of mice treated with S. cerevisiae 905.

\section{INTRODUCTION}

Probiotics are defined as live micro-organisms that when administered in adequate amounts confer a health benefit to the host (Food and Agriculture Organization of the United Nations \& World Health Organization, 2002). These microorganisms are widely used in pharmaceutical preparations and fermented dairy products. Lactobacilli and Bifidobacteria are typically found in probiotic products for humans, as well as some yeasts such as Saccharomyces boulardii.

Abbreviation: slgA, secretory $\lg A$.
S. boulardii, a non-pathogenic yeast, was isolated from lychee fruit in Indochina and grows at the unusually high temperature of $37^{\circ} \mathrm{C}$ (McFarland \& Bernasconi, 1993). It has been used for the treatment of different types of diarrhoeal diseases, such as antibiotic-associated diarrhoea (Bartlett, 1992; McFarland et al., 1995; Surawicz, 2003), Clostridium difficile-associated intestinal disease (Elmer et al., 1999; Surawicz et al., 2000; Surawicz, 2003), traveller's diarrhoea (Scarpignato \& Rampal, 1995) and diarrhoea in HIV-infected patients (Born et al., 1993).

Many mechanisms of action have been proposed to explain S. boulardii protection and they have been summarized by 
Czerucka \& Rampal (2002). It was demonstrated that this yeast modulates the immune system (Buts et al., 1990; Rodrigues et al., 2000), degrades C. difficile toxins A and $\mathrm{B}$ and their respective receptors on colonic mucosa (Pothoulakis et al., 1993; Castagliuolo et al., 1999; Qamar et al., 2001), inhibits cholera toxin action (Czerucka et al., 1994; Brandão et al., 1998; Neves et al., 2002), modulates the transduction pathway induced by enteropathogenic and enterohaemorrhagic Escherichia coli (Czerucka et al., 2000; Dahan et al., 2003), stimulates enzymic activities (Jahn et al., 1996) and fixes some enterobacteria on its surface (Gedek, 1999).

Until now $S$. boulardii is the only yeast commercialized as a probiotic for humans, but some authors have suggested the use of other yeast species or genera based essentially on in vitro assays and very few clinical trials (Kovacs \& Berk, 2000; Kumura et al., 2004; Van der Aa Kühle et al., 2005). Genetically, Saccharomyces cerevisiae is virtually identical to S. boulardii, but they are metabolically very different (Fietto et al., 2004). This leads to the question whether other strains of Saccharomyces, as well as S. boulardii, possess biotherapeutic properties. Brazil is well known for its rich biodiversity in terms of animal, vegetal and microbial species, and yeast with probiotic properties certainly could be screened from Brazilian environmental and agroindustrial sources. Previous results obtained in our laboratory showed that S. cerevisiae strain 905, isolated from 'cachaça' production, was able to colonize and survive in the gastrointestinal tract of germ-free and conventional mice, and to protect them against experimental infections with Salmonella enterica serotype Typhimurium and C. difficile (Martins et al., 2005). Additional results obtained in the same study showed that this protective effect was not due to reduction of the intestinal populations of the pathogenic bacteria.

The aim of the present work was to examine the effects of S. cerevisiae strain 905 on the translocation of Salm. Typhimurium, as well as its effect on some aspects of the immune system, in gnotobiotic and conventional mice in order to investigate the possible mechanism of protection.

\section{METHODS}

Mice. Germ-free 21-23 day-old NIH mice (Taconic) were used in this work. The animals were housed in flexible plastic isolators (Standard Safety Equipment Company) and handled according to established procedures (Pleasants, 1974). Experiments with gnotobiotic mice were carried out in micro-isolators (UNO Roestvaststaal). Conventional NIH mice were derived from the germ-free colony and only used after at least two generations following the conventionalization. Water and commercial autoclavable diet (Nuvital) were sterilized by steam and administered ad libitum to all the animals. Mice pertaining to the same group were housed together, but respecting a maximum number of 5 to 6 animals per cage. Conventional mice were maintained in an open animal house and a controlled lighting ( $12 \mathrm{~h}$ light, $12 \mathrm{~h}$ dark) was used for all the animals. All experimental procedures were carried out according to the standards set forth by the National Research Council (1996).
The study was approved by the Ethics Committee in Animal Experimentation of the Federal University of Minas Gerais (CETEA/ UFMG, protocol no. 075/04).

Micro-organisms. The yeasts used in this work were from the yeast bank of Dr Carlos A. Rosa, Laboratory of Yeast Ecology and Biotechnology, UFMG. The identity of strain 905 was determined as S. cerevisiae using the computer program YEASTCOMPARE (Ciriello \& Lachance, 2001). Salm. Typhimurium of human origin and E. coli $\mathrm{B}_{41}$ isolates were provided by the Laboratory of Microbial Ecology and Physiology, Department of Microbiology, UFMG. Salm. Typhimurium and E. coli $\mathrm{B}_{41}$ (0101: K99:F41) were maintained at $-70{ }^{\circ} \mathrm{C}$ in brain heart infusion (BHI) broth (Difco) containing $20 \%$ glycerol. S. cerevisiae 905 was maintained at $-86^{\circ} \mathrm{C}$ in medium containing $1 \%$ yeast extract, $2 \%$ peptone, $25 \%$ glycerol. The identity of the bacteria was regularly confirmed by Gram staining and using the API 20E identification kit (BioMérieux). The purity of yeast cultures was routinely confirmed by inoculating onto BHI agar (Difco) supplemented with $100 \mathrm{mg}$ cycloheximide $1^{-1}$, as well as by microscopic examination of faecal dilution from yeast mono-associated gnotobiotic mice.

Mono-association and treatment. Yeast were grown in YPG ( $1 \%$ yeast extract, $2 \%$ peptone, $2 \%$ glucose) broth for $24 \mathrm{~h}$ at $37^{\circ} \mathrm{C}$ and 150 r.p.m. The culture was then concentrated tenfold by centrifugation to obtain $9.0 \log$ c.f.u. $\mathrm{ml}^{-1}$ of S. cerevisiae 905 . For monoassociation (experimental gnotobiotic group), a single dose of $0.1 \mathrm{ml}$ was administered to germ-free mice by intragastric intubation 10 days before the analyses or the experimental challenge with pathogenic bacteria. For treatment (experimental conventional group), the same dose was administered daily to conventional mice, 10 days before the analyses or the challenge and, in this last case, during all the remaining experimental period of infection. As a control, germ-free (control gnotobiotic group) and conventional (control conventional group) mice were submitted to inoculation with $0.9 \%$ saline according to the same schedule as the respective experimental groups.

Yeast translocation. S. cerevisiae 905 translocation to Peyer's patches, mesenteric lymph nodes, liver and spleen of gnotobiotic and conventional mice was determined after 10 days of yeast monoassociation or treatment, respectively. Mice were sacrificed and organs were aseptically collected, weighed, and macerated in sterile PBS $(1: 10, \mathrm{w} / \mathrm{v})$. Serial tenfold dilutions were prepared and $100 \mu \mathrm{l}$ aliquots were plated onto Sabouraud dextrose agar (Difco). Colonies were counted after incubation at $37^{\circ} \mathrm{C}$ for $48 \mathrm{~h}$.

Clearance. Control and experimental gnotobiotic groups were tested for their capacity to clear a Gram-negative bacterium injected systemically. Each mouse was injected with $0.2 \mathrm{ml}$ suspension containing $10^{8}$ c.f.u. E. coli $\mathrm{B}_{41} \mathrm{ml}^{-1}$ in sterile $\mathrm{PBS}$ in the tail vein after ether anaesthesia. Blood samples were taken from the retro-orbital plexus shortly after the injection (time 0 ) and 15, 30, 60 and $90 \mathrm{~min}$ after the injection. Tenfold serial dilutions of $0.02 \mathrm{ml}$ blood were plated and cultured onto MacConkey agar (Difco). Dishes were incubated at $37^{\circ} \mathrm{C}$ for $24 \mathrm{~h}$ and colonies were counted. Results are the number of c.f.u. expressed as a percentage of the counts obtained at time $0(100 \%)$.

Histological and morphometrical examinations. After sacrifice by cervical dislocation, tissue samples from the liver of control and experimental gnotobiotic mice were fixed in buffered $4 \%$ formaldehyde and processed for paraffin embedding. The histopathological sections $(3-5 \mu \mathrm{m})$ were stained with haematoxylin-eosin. The slides were coded and examined by a single pathologist, who was unaware of the experimental conditions of each sample. For morphometrical examination of the liver, images were obtained with a JVC TK-1270/ RGB microcamera and the KS 300 software built in a Kontron 
Elektronick/Carl Zeiss image analyser (Oberkohen). Küpffer cells were counted for each of 100 hepatocytes in each of 12 fields of view of the samples.

Immunoglobulin determination. After sacrifice, the small intestine of gnotobiotic and conventional mice from both experimental and control groups was removed, and the contents were withdrawn, weighed and suspended at $500 \mathrm{mg}$ intestinal contents per $2.0 \mathrm{ml}$ PBS. After centrifugation at $2000 \mathrm{~g}$ for $30 \mathrm{~min}$ at $4{ }^{\circ} \mathrm{C}$, the supernatant fluid was collected and kept frozen at $-70{ }^{\circ} \mathrm{C}$ until use. Serum samples were obtained after blood collection from the axillary plexus. Immunoglobulin levels in intestinal fluid and serum were evaluated by capture ELISA using goat anti-mouse $\operatorname{IgA}$, IgG and IgM (Sigma) and horseradish peroxidase-conjugated goat antimouse IgA, IgG and IgM (Sigma). Colour was developed with $o$-phenylenediamine (Sigma) and absorbance at $492 \mathrm{~nm}$ was determined with an ELISA plate reader (Bio-Rad). The concentrations of each immunoglobulin were determined using the respective purified mouse standard (Southern Biotechnology).

Experimental infection. Salm. Typhimurium was grown in BHI broth (Difco) at $37^{\circ} \mathrm{C}$ for $18-24 \mathrm{~h}$ under aerobic conditions. Mice were inoculated intragastrically with $0.1 \mathrm{ml}$ bacterial suspension containing 2.0 and $4.0 \log$ c.f.u. for gnotobiotic (control and experimental groups) and conventional mice (control and experimental groups), respectively.

Salm. Typhimurium translocation. Bacteria translocation to mesenteric lymph nodes, liver and spleen was determined after 3 days of challenge for gnotobiotic mice (control and experimental groups), and after 5 and 10 days of challenge for conventional mice (control and experimental groups). After sacrifice, the organs were aseptically collected, weighed, and macerated in sterile PBS $(1: 10$, $\mathrm{w} / \mathrm{v})$. Serial tenfold dilutions were prepared and $100 \mu \mathrm{l}$ aliquots were plated onto MacConkey agar (Difco). Colonies were counted after incubation at $37^{\circ} \mathrm{C}$ for $24 \mathrm{~h}$.

Statistical analysis. For obtaining data on the translocation, clearance, immunoglobulin production and histology, all groups consisted of 4 to 11 animals. The results were expressed as the mean of at least two independent experiments. The data were statistically analysed using the Student's $t$-test at a probability level of 0.05 . Statistical analyses were performed using the programme Sigma Stat (Jandel Scientific Software; version 1.0).

\section{RESULTS}

The results in Fig. 1 show that S. cerevisiae strain 905 translocated in low levels to mesenteric lymph nodes and/or Peyer's patches, and was not found in liver or spleen of experimental gnotobiotic and conventional mice. The presence of the yeast in these lymphoid organs did not result in an increase in the organ weight : body weight ratios (data not shown).

Similar translocation levels of Salm. Typhimurium to mesenteric lymph nodes and spleen were observed in control and experimental gnotobiotic mice (Fig. 2). However, translocation to the liver was noted only in control gnotobiotic animals (Fig. 2). In conventional mice, translocation of Salmonella to mesenteric lymph nodes, spleen and liver was detected in control animals but not in experimental mice, both after 5 and 10 days of challenge (Fig. 3).

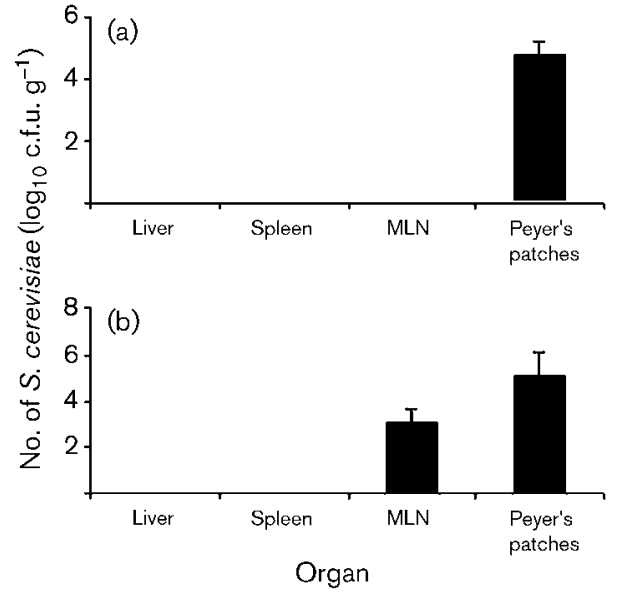

Fig. 1. Translocation of S. cerevisiae 905 to liver, spleen, mesenteric lymph nodes (MLN) and Peyer's patches in gnotobiotic (a) and conventional (b) mice, respectively, mono-associated or treated with the yeast for 10 days. Vertical bars represent SDs of the means, $n=5$ animals in each group.

The number of Küpffer cells in liver was significantly higher $(P=0.013)$ in experimental gnotobiotic mice $(52.9 \pm 15.7$ Küpffer cells per 100 hepatocytes $)$ than in control ones (38.1 \pm 9.0 Küpffer cells per 100 hepatocytes). In the experimental gnotobiotic group we observed rare mononuclear cells dispersed in the parenchyma. There was a higher nucleoplasmatic reactivity and a higher degree of hypertrophy and hyperplasia of Küpffer cells when compared to the control group. The higher number of Küpffer cells in the liver did not result in an alteration of the organ weight: body weight ratio (data not shown).

The clearance capacity for E. coli $\mathrm{B}_{41}$ from the bloodstream in experimental gnotobiotic mice was higher than that observed for control animals $(P<0.05)$ (Fig. 4). This improved clearance was not due to an increase in the size

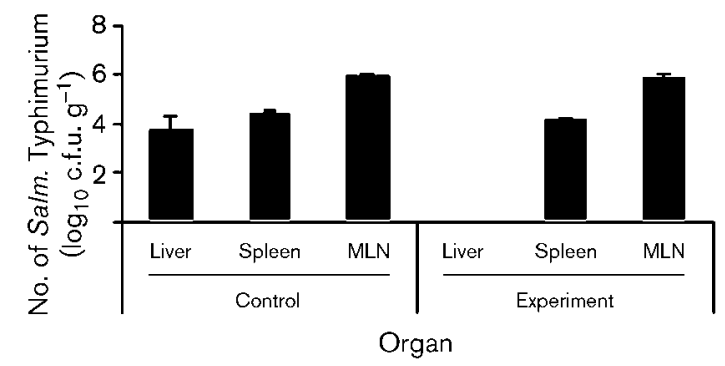

Fig. 2. Translocation of Salm. Typhimurium to liver, spleen and mesenteric lymph nodes (MLN) in germ-free mice mono-associated (experimental) or not (control) for 10 days with S. cerevisiae 905, and then challenged intragastrically with $2.0 \log$ c.f.u. of the bacteria. Determination was performed by day 3 after the pathogenic challenge. Vertical bars represent SDs of the means, $n=4$ animals in each group. 


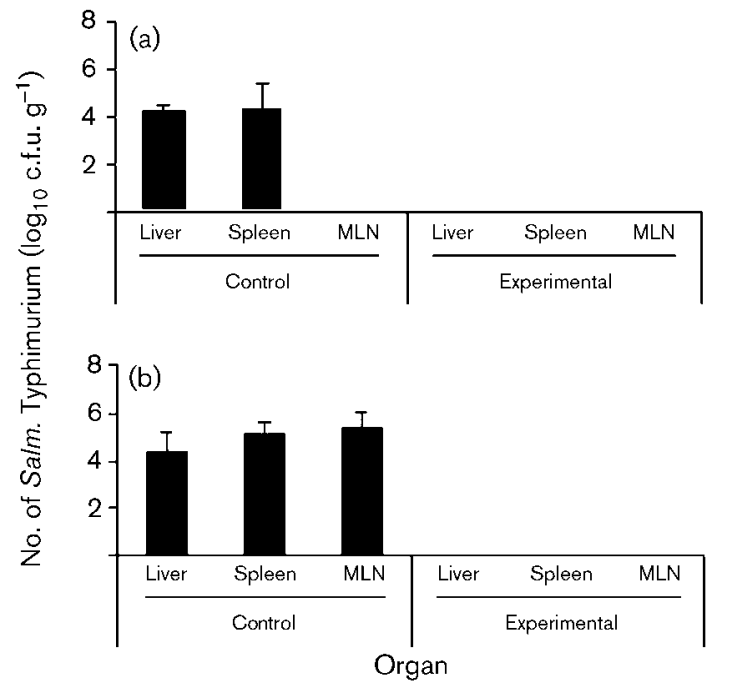

Fig. 3. Translocation of Salm. Typhimurium to liver, spleen and mesenteric lymph nodes (MLN) in experimental or control conventional mice challenged intragastrically with $4.0 \mathrm{log}$ c.f.u. of the bacteria. Determination was performed by days 5 (a) and 10 (b) after the pathogenic challenge. Vertical bars represent SDs of the means, $n=4$ animals in each group.

of livers of experimental gnotobiotic mice, as hepatomegalia was not observed.

Fig. 5. shows the influence of S. cerevisiae 905 on levels of IgA in intestinal fluid and serum of gnotobiotic mice. A statistically significant difference $(P<0.05)$ between control and experimental groups was observed for levels of secretory

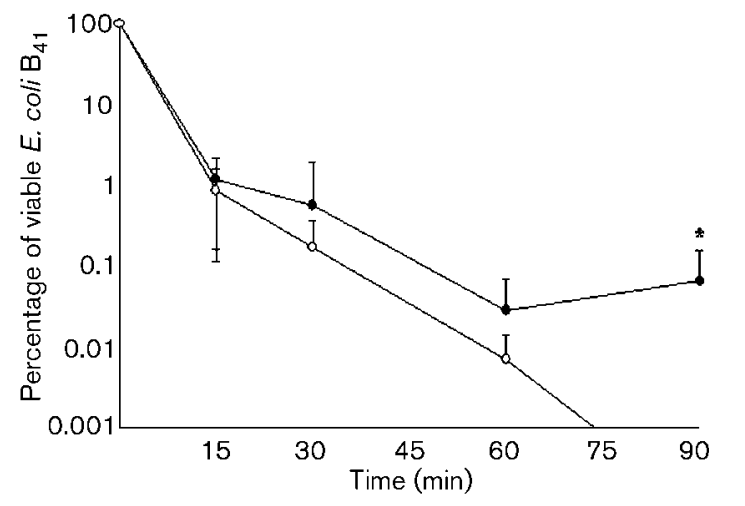

Fig. 4. Clearance of $E$. coli $\mathrm{B}_{41}$ from the bloodstream of control (O) and experimental $(\bigcirc)$ gnotobiotic mice. The results are expressed as the percentage of viable cells $(\mathrm{ml} \mathrm{blood})^{-1}$ in relation to time $0(100 \%)$. Each point represents the mean of 11 mice from 2 representative experiments. Vertical bars represent SDs of the means. *Indicates statistically significant difference between mono-associated and germ-free mice as evaluated by Student's $t$-test $(P<0.05), n=11$ animals in each group.
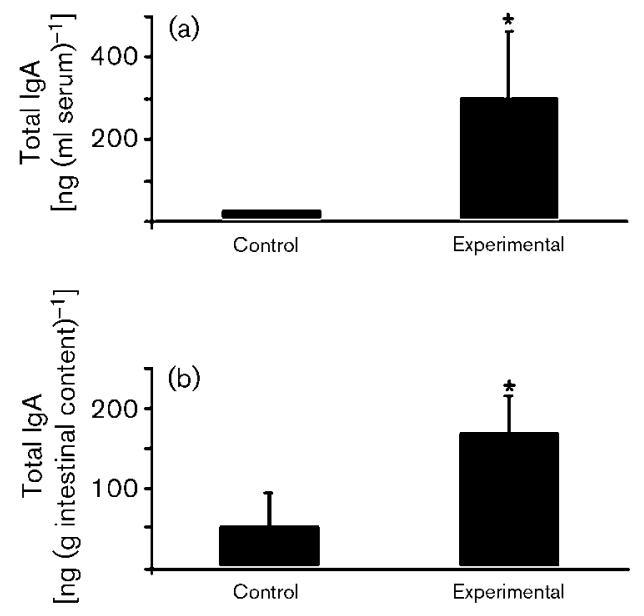

Fig. 5. Levels of total serum $\lg A$ (a) and total intestinal $\operatorname{sig} A$ (b) of control and experimental gnotobiotic mice. The results are expressed as means of immunoglobulin concentration [ng ( $\mathrm{g}$ intestinal content) ${ }^{-1}$ or $\left.\mathrm{ng}(\mathrm{ml} \text { serum })^{-1}\right]$. Vertical bars represent SDs of the means. *Indicates statistically significant difference between control and experimental groups as evaluated by the Student's $t$-test $(P<0.05), n=9$ animals in each group.

$\operatorname{IgA}(\operatorname{sIg} \mathrm{A})$ in the intestinal content (Fig. 5b), and serum IgA (Fig. 5a) and IgM in serum $\left(5973 \pm 1342 \mathrm{ng} \mathrm{ml}^{-1}\right.$ control gnotobiotic mice versus $10457-666 \mathrm{ng} \mathrm{ml}^{-1}$ experimental gnotobiotic mice, $P=0.014, n=4$ animals in each group). For the other determinations, a discrete but not statistically significant difference was observed: intestinal IgM $\left(56 \pm 16 \mathrm{ng} \mathrm{ml}^{-1}\right.$ control mice versus $69 \pm 3 \mathrm{ng} \mathrm{ml}^{-1}$ experimental mice, $P=0.21, n=4$ animals in each group); serum IgG $\left(16633 \pm 6060 \mathrm{ng} \mathrm{ml}^{-1}\right.$ control mice versus $20278 \pm 8670 \mathrm{ng} \mathrm{ml}^{-1}$ experimental mice, $P=0.32 . n=9$ animals in each group); intestinal $\operatorname{IgG}\left(225 \pm 86 \mathrm{ng} \mathrm{ml}^{-1}\right.$ control mice versus $268 \pm 48 \mathrm{ng} \mathrm{ml}^{-1}$ experimental mice, $P=0.32, n=6$ animals in each group). In conventional mice an increase in total IgG and IgM was observed only in the intestinal content $\left(\operatorname{IgG} 123 \pm 6 \mathrm{ng} \mathrm{ml}^{-1}\right.$ control mice versus $181 \pm 23 \mathrm{ng} \mathrm{ml}^{-1}$ experimental mice, $P=0.16, n=4$ animals in each group; IgM $12 \pm 2 \mathrm{ng} \mathrm{ml}^{-1}$ control mice versus $21 \pm 9 \mathrm{ng} \mathrm{ml}^{-1}$ experimental mice, $P=0.38 . n=4$ animals in each group), but these differences were not statistically significant. No alterations were observed in the levels of immunoglobulins in serum of conventional mice (data not shown).

\section{DISCUSSION}

Very few yeasts have been studied as possible biotherapeutics and, at the moment, $S$. boulardii is practically the only yeast commercialized for human use. However, other Saccharomyces spp. or members of other yeast genera with similar or even better therapeutic properties could certainly be isolated from environmental or agroindustrial sources. As one of the largest and most biodiverse countries, Brazil 
may provide a rich source of micro-organisms for potential probiotic use. In a previous work (Martins et al., 2005), various S. cerevisiae strains isolated from different Brazilian environments (insect associated, tropical fruit, cheese and 'cachaça' production) were pre-selected for in vitro resistance to simulated gastrointestinal conditions, and then tested in vivo for their capacities to colonize the digestive tract without pathogenic consequences and to protect against pathogenic challenge of gnotobiotic and conventional mice. S. cerevisiae strain 905 showed the best characteristics as demonstrated by survival and histopathological data after experimental challenge with Salm. Typhimurium and C. difficile. However, the same study showed that this protective effect was not due to the reduction of the intestinal populations of the pathogenic bacteria (Martins et al., 2005). This result was similar to that previously observed with $S$. boulardii (Rodrigues et al., 1996). Thus, other antagonistic mechanisms could be responsible for the protective effect conferred by S. cerevisiae 905 , such as immunomodulation, modulation of toxin production or action, and/or competition for nutrients or adhesion sites.

Like other probiotics, such as $S$. boulardii (Rodrigues et al., 1996), Bifidobacterium longum (Silva et al., 2004) and Lactobacillus acidophilus (Moura et al., 2001), S. cerevisiae 905 was rapidly eliminated from the digestive tract of mammals harbouring a complex intestinal microbiota (2-3 days) and for this reason daily ingestion of these micro-organisms was necessary to maintain artificially high viable levels in the gastrointestinal ecosystem of conventional animals. On the other hand, its implantation was possible in germ-free animals using a single dose. Gnotobiotic mice were used in the present study to obtain a simplified in vivo ecosystem allowing the observation of ecological interactions between the probiotic, bacterial pathogen and the host. The results were compared with those obtained using a similar experimental design but with animals harbouring an indigenous gastrointestinal microbiota (conventional).

In mice, Salm. Typhimurium is described as a facultative intracellular parasite that grows primarily inside the macrophages of liver and spleen. It has been shown that within $30 \mathrm{~min}$ of infection, invasive Salm. Typhimurium entered $M$ cells found within the follicle-associated epithelium (FAE) of Peyer's patches. At $60 \mathrm{~min}$, internalized bacteria were cytotoxic for the $\mathrm{M}$ cells and the dead cell formed a gap in the FAE, which allowed bacteria to invade adjacent enterocytes (Jones \& Falkow, 1996) or rapidly migrate to a number of sites in the body, including the spleen and liver, where they replicated inside phagocytic cells. This dissemination stimulates the formation of neutrophil-rich and mononuclear-cell-rich microabscesses, which subsequently evolve into granulomas containing activated mononuclear cells.

The development of an immune response toward foreign antigens of microbial and viral origin provides a means through which potentially pathogenic organisms are recognized and controlled. However, this response cannot be exacerbated to the point of causing tissue damage and disease. There is an extensive body of literature addressing the possible health benefits associated with the consumption of probiotics. Probiotic micro-organisms may exert their effects through immunomodulation, particularly by regulation of pro- and anti-inflammatory cytokine levels (Rodrigues et al., 2000; Silva et al., 2004) to obtain an efficient, but not excessive response during an infectious aggression.

As observed with S. boulardii (Rodrigues et al., 2000), S. cerevisiae strain 905 translocated in low levels to mesenteric lymph nodes and/or Peyer's patches, but not to liver or spleen. The translocation is involved in the pathogenesis of invasive intestinal bacterial infection, but under normal conditions, a physiological translocation also occurs and would be responsible for the modulation of the host immune system by the indigenous microbiota (Berg, 1996). Translocation of a probiotic limited to local lymphoid organs, such as Peyer's patches and mesenteric lymph nodes, could bring about antigen presentation events, triggering immune responses in situ and systemically. In addition, before the development of T-cell-mediated responses, innate immunity events could be triggered by the presence of the probiotic in the gut-associated lymphoid tissues. Consequently, the low level of limited translocation observed for S. cerevisiae strain 905 could be beneficial in priming the host immune response to improve defence against overt or opportunist pathogens.

The reduced translocation of Salm. Typhimurium observed in mice treated with S. cerevisiae 905 could explain the lower number of hepatic inflammatory foci in these animals 28 days after the challenge with the enteropathogenic bacteria as observed in our previous study (Martins et al., 2005). The translocation of Salm. Typhimurium to liver and spleen of control animals, without detection of the pathogen in lymph nodes (Fig. 3a), could be explained by more physical damage to the intestinal epithelium in this animal group. As described by Berg (1995), translocation to liver could occur via intracellular passage (lymphatic route, via lymph nodes) or extracellular passage (vascular route, due to physical damage to the intestinal epithelium). Reduced levels of translocation have been also observed in various animal models (burn injury, liver injury, experimental immunosuppression, abdominal infection) using probiotic products based on bacteria (Chiva et al., 2002; Gun et al., 2005) and yeast (Peret et al., 1998; Herek et al., 2004). It seems that all the components of the host immune system including mucosal, cell-mediated and humoral immunities - are involved in controlling bacterial translocation. sIgA is thought to inhibit the close association of pathogenic bacteria with the mucosal epithelium, and so to reduce bacterial penetration. Cell-mediated immunity in the lamina propria and in lymphoid organs provides a second line of host defence against bacterial translocation. Serum immunoglobulins probably act as opsonins to increase the 
effectiveness of phagocytosis by macrophages and polymorphonuclear leukocytes, and subsequent killing of translocating bacteria. In the case of successful translocation, the reticuloendothelial system (RES) plays a key role in removing micro-organisms from the circulatory system, and hepatic phagocytosis by Küppfer cells accounts for more than $80 \%$ of the RES function (Saba, 1970). Glucan and other Saccharomyces extracts are important RES stimulators. Proliferation of pluripotent haematopoietic stem cells, granulocyte-macrophage colony-forming cells and erythroid colony-forming cells in murine bone marrow has been demonstrated after glucan administration (Patchen \& McVittie, 1982). Furthermore, after glucan administration, there is an increased production of interleukin 1 either by a direct effect on macrophages or indirectly by an increase on colony stimulating factor(s) production from glucanstimulated T-cells (Hamuro et al., 1982).

It is well known that Küppfer cells represent one of the largest populations of tissue macrophages and, together with neutrophils, have been implicated as being responsible for the clearance of bacteria from the bloodstream (Hirakata et al., 1991; Gregory et al., 1996). The higher number of Küpffer cells in liver from experimental gnotobiotic mice was also observed when germ-free mice were monoassociated with Lactobacillus delbrueckii UFV-H2B20 (Neumann et al., 1998) and S. boulardii (Rodrigues et al., 2000), and this increase was simultaneous with a higher clearance of systematically injected pathogenic bacterium. When tested in the present study, the clearance capacity of $E$. coli $\mathrm{B}_{41}$ from the bloodstream in experimental gnotobiotic mice was higher than that observed for control gnotobiotic animals. Taken together, the results suggest that, in this experimental model, the higher number of Küppfer cells in the liver of experimental gnotobiotic mice was responsible for the improved clearance observed when compared with control gnotobiotic animals.

To assess if a humoral immune response could be related to the protective effect observed against Salm. Typhimurium, we determined immunoglobulin concentrations in the intestinal fluid and serum of yeast-treated mice. S. cerevisiae strain 905 enhanced the local (intestinal fluid) as well as the systemic (serum) production of this immunoglobulin. sIgA represents an immune barrier against the adhesion of pathogens to the intestinal mucosa, binding either to the surface of bacteria and trapping them in the mucous layer of the intestinal epithelia, or to bacterial surface molecules that mediate adhesion to epithelial cells, thus preventing translocation to internal organs (Hajishengallis et al., 1992). The ability to stimulate the production of sIgA is not the same for different micro-organisms, and in gnotobiotic mice Gram-negative bacteria and yeast generally induce a higher stimulation than Gram-positive bacteria (Moreau et al., 1982; Neumann et al., 1998; Rodrigues et al., 2000).

As expected and observed with other probiotics (Rodrigues et al., 1996; Silva et al., 2004), the protection offered by $S$. cerevisiae 905 against the pathogenic challenge was different between conventional and gnotobiotic animals due to the complementary protective effect from the indigenous intestinal microbiota and from the biotherapeutic agent in the first case. Germ-free animals are generally more susceptible to experimental infection due to both the lack of ecological competition in the gastrointestinal lumen and to the underdeveloped immune system in the internal compartment.

The present findings suggest that S. cerevisiae 905 may have potential as a probiotic as it reduces the translocation levels of Salm. Typhimurium. Host immunomodulation by the yeast may be one explanation for its protection against Salm. Typhimurium, and against $C$. difficile infections as observed in our previous study (Martins et al., 2005). Probiotic treatment before experimental infection in animal models may not necessarily reproduce all the mechanisms operating in humans, and the extrapolation from animal data to therapeutic effects in humans must be interpreted cautiously. However, probiotic efficacy against experimental pathogenic challenge can only be predicted by such extrapolations, and the use of this model prior to human trials was recommended by the Food and Agriculture Organization of the United Nations \& World Health Organization (2002).

\section{ACKNOWLEDGEMENTS}

This work was supported by grants from Conselho Nacional de Desenvolvimento Científico e Tecnológico (CNPq) and Fundação de Amparo à Pesquisa do Estado de Minas Gerais (FAPEMIG). We thank Dr Ana Maria Caetano de Faria for the standard purified IgA, IgG and IgM, and Maria Gorete Barbosa Ribas and Antônio Mesquita Vaz for their valuable technical assistance.

\section{REFERENCES}

Bartlett, J. G. (1992). Antibiotic-associated diarrhea. Clin Infect Dis 15, 573-581.

Berg, R. D. (1995). Bacterial translocation from the gastrointestinal tract. Trends Microbiol 3, 149-154.

Berg, R. D. (1996). The indigenous gastrointestinal microflora. Trends Microbiol 4, 430-435.

Born, P., Lersch, C., Zimmerhackl, B. \& Claassen, M. (1993). The Saccharomyces boulardii therapy of HIV-associated diarrhea. Dtsch Med Wochenschr 118, 765.

Brandão, R. L., Castro, I. M., Bambirra, E. A., Amaral, S. C., Fietto, L. G., Tropia, M. J. M., Neves, M. J., Dos Santos, R. G., Gomes, N. C. M. \& Nicoli, J. R. (1998). Intracellular signal triggered by cholera toxin in Saccharomyces boulardii and Saccharomyces cerevisiae. Appl Environ Microbiol 64, 564-568.

Buts, J. P., Bernasconi, P., Vaerman, J. P. \& Dive, C. (1990). Stimulation of secretory IgA and secretory component of immunoglobulins in small intestine of rats treated with Saccharomyces boulardii. Dig Dis Sci 35, 251-256.

Castagliuolo, I., Riegler, M. F., Valenick, L., Lamont, J. T. \& Pothoulakis, C. (1999). Saccharomyces boulardii protease inhibits the 
effects of Clostridium difficile toxins A and B in human colonic mucosa. Infect Immun 67, 302-307.

Chiva, M., Soriano, G., Rochat, I., Peralta, C., Rochat, F., Llovet, T., Mirelis, B., Schiffrin, E. J., Guarner, C. \& Balanzo, J. (2002). Effect of Lactobacillus johnsonii Lal and antioxidants on intestinal flora and bacterial translocation in rats with experimental cirrhosis. $J$ Hepatol 37, 456-462.

Ciriello, C. J. \& Lachance, M. A. (2001). YEASTCOMPARE. University of Western Ontario, London, ON, Canada.

Czerucka, D. \& Rampal, P. (2002). Experimental effects of Saccharomyces boulardii on diarrheal pathogens. Microbes Infect 4, 733-739.

Czerucka, D., Roux, I. \& Rampal, P. (1994). Saccharomyces boulardii inhibits secretagogue-mediated adenosine $3^{\prime}, 5^{\prime}$-cyclic monophosphate induction in intestinal cells. Gastroenterology 106, 65-72.

Czerucka, D., Dahan, S., Mograbi, B., Rossi, B. \& Rampal, P. (2000). Saccharomyces boulardii preserves the barrier function and modulates the transduction pathway induced in enteropathogenic Escherichia coli-infected T84 cells. Infect Immun 68, 5998-6004.

Dahan, S., Dalmasso, G., Imbert, V., Peyron, J.-F., Rampal, P. \& Czerucka, D. (2003). Saccharomyces boulardii interferes with enterohemorrhagic Escherichia coli-induced signaling pathways in T84 cells. Infect Immun 71, 766-773.

Elmer, G. W., McFarland, L. V., Surawicz, C. M., Danko, L. \& Greenberg, R. N. (1999). Behaviour of Saccharomyces boulardii in recurrent Clostridium difficile disease patients. Aliment Pharmacol Ther 13, 1663-1668.

Fietto, J. L. R., Araújo, R. S., Valadão, F. N., Fietto, L. G., Brandão, R. L., Neves, M. J., Gomes, C. O., Nicoli, J. R. \& Castro, I. M. (2004). Molecular and physiological comparisons between Saccharomyces cerevisiae and Saccharomyces boulardii. Can J Microbiol 50, 615-621.

Food and Agriculture Organization of the United Nations \& World Health Organization (2002). Guidelines for the Evaluation of Probiotics in Food, Food and Agriculture Organization of the United Nations and World Health Organization Working Group Report, London, Ontario, Canada, April 30-May 12002.

Gregory, S. H., Sagnimeni, A. J. \& Wing, E. J. (1996). Bacteria in the bloodstream are trapped in the liver and killed by immigrating neutrophils. J Immunol 157, 2514-2520.

Gedek, B. R. (1999). Adherence of Escherichia coli serogroup O157 and the Salmonella typhimurium mutant DT 104 to the surface of Saccharomyces boulardii. Mycoses 42, 261-264.

Gun, F., Salman, T., Gurler, N. \& Olgac, V. (2005). Effect of probiotic supplementation on bacterial translocation in thermal injury. Surg Today 35, 760-764.

Hajishengallis, G., Nikolova, E. \& Russel, M. W. (1992). Inhibition of Streptococcus mutans adherence to saliva-coated hydroxyapatite by human secretory immunoglobulin A antibodies to the cell surface protein antigen I/II: reversal by IgA 1 protease cleavage. Infect Immun 60, 5057-5064

Hamuro, J., Akiyama, Y., Iguchi, Y., Isawa, M. \& Matsuo, T. (1982). Distinct roles of serum factors induced by a $\mathrm{T}$ cell specific immune adjuvant lentinan in cellular immune responses. Int J Immunopharmacol 4, 268.

Herek, O., Kara, I. G. \& Kaleli, I. (2004). Effects of antibiotics and Saccharomyces boulardii on bacterial translocation in burn injury. Surg Today 34, 256-260.

Hirakata, Y., Tomono, K., Tateda, K., Matsumoto, T., Furuya, N., Shimoguchi, K., Kaku, M. \& Yamaguchi, K. (1991). Role of bacterial association with Küpffer cells in occurrence of endogenous systemic bacteremia. Infect Immun 59, 289-294.

Jahn, H. U., Ullrich, R., Schneider, T., Liehr, R. M., Schieferdecker, H. L., Holst, H. \& Zeitz, M. (1996). Immunological and trophical effects of Saccharomyces boulardii on the small intestine in healthy human volunteers. Digestion 57, 95-104.

Jones, B. D. \& Falkow, S. (1996). Salmonellosis: host immune responses and bacterial virulence determinants. Annu Rev Immunol 14, 533-561.

Kovacs, D. J. \& Berk, T. (2000). Recurrent Clostridium difficileassociated diarrhea and colitis treated with Saccharomyces cerevisiae (baker's yeast) in combination with antibiotic therapy: a case report. J Am Board Farm Pract 13, 138-140.

Kumura, H., Tanoue, Y., Tsukahara, M., Tanaka, T. \& Shimazaki, K. (2004). Screening of dairy yeast strains for probiotic applications. J Dairy Sci 87, 4050-4056.

Martins, F. S., Nardi, R. M. D., Arantes, R. M. E., Rosa, C. A., Neves, M. J. \& Nicoli, J. R. (2005). Screening of yeast as probiotic based on capacities to colonize the gastrointestinal tract and to protect against enteropathogen challenge in mice. J Gen Appl Microbiol 51, 83-92.

McFarland, L. V. \& Bernasconi, P. (1993). Saccharomyces boulardii: a review of an innovative biotherapeutic agent. Microb Ecol Health Dis 6, 157-171

McFarland, L. V., Surawicz, C. M., Greenberg, R. N., Elmer, G. W., Moyer, K. A., Melcher, S. A., Bowen, K. E. \& Cox, J. L. (1995). Prevention of $\beta$-lactam-associated diarrhea by Saccharomyces boulardii compared with placebo. Am J Gastroenterol 90, 439-448.

Moreau, M. C., Raibaud, P. \& Muller, M. C. (1982). Relation entre le développement du systéme immunitaire intestinal à IgA et l'établissement de la flore microbienne dans le tube digestif de souris holoxênique. Ann Inst Pasteur Immunol 133B, 29-39.

Moura, L. N., Neumann, E., Vieira, L. Q. \& Nicoli, J. R. (2001). Protection by Lactobacillus acidophilus UFV-H2B20 against experimental oral infection with Salmonella enterica subsp. enterica ser. Typhimurium in gnotobiotic and conventional mice. $\mathrm{Br} J$ Microbiol 32, 66-69.

National Research Council (1996). Guide for the Care and Use of Laboratory Animals. Washington, DC: National Academy Press.

Neumann, E., Oliveira, M. A. P., Cabral, C. M., Moura, L. N., Nicoli, J. R., Vieira, E. C., Cara, D. C., Podoprigora, G. I. \& Vieira, L. Q. (1998). Monoassociation with Lactobacillus acidophilus UFV- $\mathrm{H}_{2} \mathrm{~B}_{20}$ stimulates the phagocytic system of germ-free mice. $\mathrm{Br} J$ Med Biol Res 31, 1565-1573.

Neves, M. J., Etchebehere, L., Brandão, R. L., Castro, I. M., Lima, M. E. \& Nicoli, J. R. (2002). Partial characterization of cholera toxin binding on membranes of Saccharomyces boulardii. Microecol Ther 29, 185-190.

Patchen, M. \& McVittie, T. (1982). Effects of a soluble glucan on hemopoietic stem cell proliferation. Int J Immunopharmacol 4, 273.

Pleasants, J. R. (1974). Gnotobiotics. In Handbook of Laboratory Animal Science, p. 119-174. Edited by E. C. Melby Jr \& N. H. Altmann. Cleveland: CRC Press.

Peret, L. A., Penna, F. J., Bambirra, E. A. \& Nicoli, J. R. (1998). Dose effect of oral Saccharomyces boulardii treatments on morbidity and mortality in immunosuppressed mice. J Med Microbiol 47, 111-116. Pothoulakis, C., Kelly, C. P., Joshi, M. A., Gao, N., O’Keane, C. J., Castagliuolo, I. \& Lamont, J. T. (1993). Saccharomyces boulardit inhibits Clostridium difficile toxin A binding and enterotoxicity in rat ileum. Gastroenterology 104, 1108-1115.

Qamar, A., Aboudola, S., Warny, M., Michetti, P., Pothoulakis, C., Lamont, J. T. \& Kelly, C. P. (2001). Saccharomyces boulardii stimulates intestinal immunoglobulin A immune response to Clostridium difficile toxin A in mice. Infect Immun 69, 2762-2765.

Rodrigues, A. C., Nardi, R. M., Bambirra, E. A., Vieira, E. C. \& Nicoli, J. R. (1996). Effect of Saccharomyces boulardii against experimental oral infection with Salmonella typhimurium and Shigella flexneri in conventional and gnotobiotic mice. J Appl Bacteriol 81, 251-256. 
Rodrigues, A. C., Cara, D. C., Fretez, S. H. G. G., Cunha, F. O., Vieira, E. C., Nicoli, J. R. \& Vieira, L. Q. (2000). Saccharomyces boulardii stimulates sIgA production and the phagocytic system of gnotobiotic mice. J Appl Microbiol 89, 404-414.

Saba, T. M. (1970). Physiology and physiopathology of the reticuloendothelial system. Arch Intern Med 126, 1031-1052.

Scarpignato, C. \& Rampal, P. (1995). Prevention and treatment of traveler's diarrhea: a clinical pharmacological approach. Chemotherapy 41, 48-81.

Silva, A. M., Barbosa, F. H. F., Duarte, R., Vieira, L. Q., Arantes, R. M. E. \& Nicoli, J. R. (2004). Effect of Bifidobacterium longum ingestion on experimental salmonellosis in mice. J Appl Microbiol 97, 29-37.
Surawicz, C. M. (2003). Probiotics, antibiotic-associated diarrhoea and Clostridium difficile diarrhoea in humans. Best Pract Res Clin Gastroenterol 17, 775-783.

Surawicz, C. M., McFarland, L. V., Greenberg, R. N., Rubin, M., Fekety, R., Mulligan, M. E., Garcia, R. J., Brandmarker, S., Bowen, K. \& other authors (2000). The search for a better treatment for recurrent Clostridium difficile disease: use of high-dose vancomycin combined with Saccharomyces boulardii. Clin Infect Dis 31, 1012-1017.

Van der Aa Kühle, A., Skovgaard, K. \& Jespersen, L. (2005). In vitro screening of probiotic properties of Saccharomyces cerevisiae var. boulardii and food-borne Saccharomyces cerevisiae strains. Int J Food Microbiol 101, 29-39. 